\title{
PERAN BRAND LOVE SEBAGAI MEDIASI HEDONIC PRODUCT DAN SELF-EXPRESSIVE BRAND TERHADAP BRAND LOYALTY
}

Submitted Date :

22 Agustus 2020

Accepted Date :

2 September 2020

\author{
Amelindha Vania \\ Universitas Islam Negeri Maulana Malik Ibrahim Malang \\ amelindhavania@uin-malang.ac.id \\ Kartika Anggraeni Sudiono Putri \\ Universitas Islam Negeri Maulana Malik Ibrahim Malang \\ kartikaanggraeni@uin-malang.ac.id
}

Suggested Citation:

Carvalho, N. B., Minim, V. P. R., Nascimento, M., Vidigal, M. C. T. R., Ferreira, M. A. M., 902 Gonçalves, A. C. A., \& Minim, L. A. 2015. A discriminant function for validation of 903 the cluster analysis and behavioral prediction of the coffee market. Food Research 904 International, 77, 400-40.

Abstract:

This study aims to analyze the impact of hedonic products and self-expressive brands towards brand love and brand loyalty to Starbucks Coffee customers in Malang City. This study also analyzes the role of brand love as a mediator become an intermediary for hedonic products and self-expressive brands in influencing brand loyalty. The research object uses the Starbucks Coffee brand because Starbucks coffee is categorized as a hedonistic item and Starbucks builds a special bond with its customers. This type of research is descriptive quantitative. The research sample consisted of 125 customers of Starbucks Coffee Mall Dinoyo Malang with the sampling technique was carried out accidental sampling. Structural Equation Modelling (SEM) method using the IBM SPSS and IBM AMOS version 24.0 program is a method for analizyng data in this study. The results show that both hedonic products and self-expressive brands have a positive and significant impact on brand love. However, hedonic products and self-expressive brands do not have a direct influence on brand loyalty. Hedonic products and self-expressive brands have a significant effect on brand loyalty with the help of brand love as a mediator. Research also proves brand love has a positive and significant impact on brand loyalty.

Keywords: Brand Love dan Brand Loyalty, Hedonic Product, Self-Expressive Brand

\section{Abstrak:}

Penelitian ini bertujuan untuk menganalisis pengaruh hedonic product dan self-expressive brand terhadap brand love dan brand loyalty pada pelanggan Starbucks Coffee di Kota Malang. Penelitian ini juga menganalisis peran brand love sebagai mediator yang menjadi perantara hedonic product dan self-expressive brand dalam mempengaruhi brand loyalty. Objek penelitian menggunakan brand Starbucks Coffee dikarenakan kopi Starbucks dikategorikan sebagai barang hedon dan Starbucks membangun keterikatan khusus dengan pelanggannya. Jenis penelitian yang digunakan ialah deskriptif kuantitatif. Sampel penelitian berjumlah 125 orang pelanggan gerai Starbucks Coffee Mall Dinoyo Malang dengan teknik pengambilan sampel dilakukan secara accidental sampling. Metode Structural Equation Modelling (SEM) dengan menggunakan program IBM SPSS dan IBM AMOS versi 24.0 adalah metode untuk menganalisis data dalam penelitian ini. Diperoleh hasil penelitian bahwa baik hedonic product maupun self-expressive brand, keduanya mempunyai pengaruh yang positif dan signifikan terhadap brand love. Namun hedonic product dan self-expressive brand tidak menunjukan pengaruh langsung terhadap brand loyalty. Hedonic product dan self-expressive brand berpengaruh signifikan terhadap brand loyalty dengan bantuan brand love sebagai mediator. Penelitian juga membuktikan brand love mempunyai pengaruh yang positif dan signifikan terhadap brand loyalty.

Kata Kunci: Brand Love dan Brand Loyalty, Hedonic Product, Self-Expressive Brand

JEL Classification : M31 


\section{Latar Belakang}

Minuman kopi merupakan salah satu yang paling digemari dan populer di seluruh dunia dan memiliki peran penting dalam budaya konsumen sejak pertengahan abad ke-16. Selama beberapa dekade terakhir, kopi telah mengalami transformasi dari komoditas murni menjadi produk spesial. Manzo (2014) menjelaskan bahwa transformasi ini terbagi menjadi 3 gelombang. Gelombang pertama, konsumsi kopi dimulai pada 1960-an yang dicirikan sebagai pasar massal dengan pertumbuhan konsumsi eksponensial dengan ketersedian kopi yang melimpah. Gelombang kedua, konsumsi kopi dimulai pada 1990-an dibuktikan dengan banyak cabang kedai kopi seperti Starbucks Coffee. Kedai kopi memperkenalkan sebuah kopi spesial untuk menanggapi minat konsumen baru yang tertarik dengan kualitas kopi. Kopi menjadi produk mewah daripada hanya sekedar sebuah komoditas (Carvalho et al., 2015). Gelombang ketiga, kopi dapat dibuat oleh siapa saja dengan menggunakan alat pemanggang kecil kemudian dipromosikan pada daerah tertentu. Kopi dibuat dengan teknik pembuatan yang unik sehingga muncul istilah barista yaitu seseorang yang mengerti seluk beluk kopi dan mampu meracik serta menghadirkan sajian kopi yang khas.

Aktivitas minum kopi lebih dari sekedar mengonsumsi minuman karena ini berhubungan dengan kesenangan, pengalaman, gaya hidup dan status sosial. Perubahan dalam perilaku konsumen ini dimungkinkan karena 3 pendekatan yang saat ini menjadi ciri produk kopi bagi konsumen yaitu kesenangan, kesehatan dan keberlanjutan (International Coffee Organization (ICO), 2015). Starbucks Coffee merupakan pelopor kedai kopi yang menghadirkan estetika rasa yang berkelas dan mewakili nilai sosial konsumen. Cramer dan Antonides (2011) membuktikan bahwa pilihan makanan dan minuman lebih hedonis dibanding nilai manfaatnya. Demikian pula, kopi dipandang sebagai pengalaman emosional yang memunculkan emosi yang berbeda sesuai dengan sifat sensorisnya. Hal ini ditunjukan dengan kualitas kopi yang dihadirkan pada Starbucks Coffee. Estetika rasa kopi Starbucks Coffee pada setiap individu secara langsung berkaitan dengan preferensi, oleh karena itu individu dengan estetika rasa harus memiliki preferensi konsumen yang unggul (Hoyer \& Stokburger-Sauer, 2012).

Starbucks Coffee pertama kali membuka kedai di Seattle pada tahun 1971. Saat ini, ia memiliki cabang kedai kopi yang luas di banyak negara (21.536 toko di 64 negara) dan telah menjadi perusahaan kedai kopi terbesar di Amerika (Shirdastian et al., 2019). Starbucks Coffee membuka cabang pertama Tahun 1996 untuk gerainya yang ke 1.015 di kawasan Asia yaitu teaptnya di Kota Tokyo, Jepang. Mall Malang City Point menjadi lokasi pertama yang dipilih sebagai gerai pertama di Kota Malang, gerai ke 240 ini menandakan ekspansi Starbucks Coffee ke-19 kota di Indonesia. Desain unik dengan area semi outdoor dipilih menjadi tema gerai Starbucks Coffee di Malang dengan tujuan agar pelanggan dapat menikmati secangkir kopi dengan menghirup udara segar Malang (Rahmania, W. 2016). Pelanggan mengkonsumsi kopi dimotivasi oleh kenikmatan indera rasa kopi dan stimulasi psikofisik yang disediakan oleh kafein (Labbe et al., 2015). Kopi dianggap sebagai barang yang memiliki nilai manfaat ketika dikonsumsi untuk tujuan stimulasi atau konsumen mengharapkan konsekuensi fisiologis setelah konsumsi. Di sisi lain kopi dianggap sebagai barang hedonis ketika dikaitkan dengan pengalaman sensorik yang diberikan oleh rasanya (Messina, R. 2018). Kopi Starbucks memiliki nilai cita rasa tersendiri bagi konsumen. Konsumen meminumnya dalam rangka mencari kepuasan terutama melalui rasa dan aroma suatu pengalaman sehingga kopi starbucks dikategorikan sebagai barang hedon (hedonic product). Berbeda dengan produk yang menitikberatkan pada manfaat produk secara kebutuhan dan fungsional, hedonic product menawarkan pengalaman mengkonsumsi produk (Lu et al, 2016). Hedonic product merupakan suatu produk yang menawarkan manfaat hedonis bagi konsumen berupa kesenangan, kebahagiaan, kenikmatan dan kepuasan. Konsumsi produk hedonis didasarkan pada apa yang diinginkan konsumen yang sifatnya untuk mendapatkan pengalaman psikologis dari penggunaan produk. Reaksi emosi kemudian akan muncul dari pengalaman pembelian atau penggunaan produk (Messina, 2018).

Beberapa penelitian menunjukan bahwa hedonic product mampu membangkitkan respon emosional yang positif karena dari nilai hedonis yang diperoleh dapat memenuhi kebutuhan prestis individu, yaitu dapat menumbuhnya rasa cinta terhadap suatu merek atau brand love (Hwang and Kandampully 2012; Huber et al., 2015). Hal menarik dalam penelitian Huber et al. (2015) ialah ditemukan pengaruh atau respon yang muncul dari mengkonsumsi hedonic product berlangsung secara jangka panjang. Secara mengejutkan, tendensi dari respon hedonic product terhadap brand love tetap stabil seiring berjalannya waktu. Hal ini membuktikan bahwa elemen hedonis seperti kesenangan dan kenikmatan yang merupakan hal penting dalam persepsi konsumen terkait hubungan pelanggan dengan merek. Hedonic product lebih banyak memiliki manfaat simbolis, sehingga oleh konsumen sering digunakan sebagai sarana mengekspresikan diri maupun sebagai simbol sosial. Merek yang dapat memberikan manfaat hedonis yakni berupa kesenangan maupun kenikmatan yang tinggi akan lebih 
memberikan perasaan yang lebih bergairah terhadap merek tersebut, yang terwujud sebagai brand love. Namun penelitian Huber et al. (2015) juga menemukan bahwa dalam keterikatan pelanggan dengan merek, manfaat secara fungsional menjadi lebih substansial pengaruhnya seiring dengan meningkatnya durasi konsumsi. Oleh karena itu, walau sebuah produk yang memberikan manfaat hedonis yang besar, aspek nilai manfaat tetap harus diperhatikan.

Berdasarkan hasil penelitian yang dilakukan Putlia (2018) menyatakan bahwa motivasi hedonis menjadi penyebab respondennya mengkonsumsi Starbucks Coffee dengan rutin bahkan mereka sengaja menganggarkan pengeluaran khusus untuk mengkonsumsi Starbucks Coffee. Hal ini berkaitan dengan adanya keterikatan emosional yang dibangun Starbucks Coffee pada pelanggan. Konsumen dapat mengalami keterikatan emosional yang mendalam terhadap merek (Batra et al., 2012; Albert dan Merunka, 2013; Huber et al., 2015; Langner et al., 2015). Dalam rangka mengembangkan merek yang dicintai konsumen (brand love), konsumen harus memiliki sikap, pengalaman positif dan perasaan kedekatan secara psikologis pada merek tersebut (Alex \& Joseph, 2012). Brand love merupakan bagian yang terintegrasi dari ekspresi diri konsumen (self-expressiveness). Dengan penggunaan suatu merek tertentu dan menunjukan rasa cinta pada merek tersebut maka konsumen secara tidak langsung dapat mengekspresikan dirinya kepada orang lain (Huber et al., 2015 dan Wallace et al., 2014). Di luar fungsi dasar merek sebagai alat indentifikasi produk, keberadaan sebuah merek sebagai salah satu atribut produk dinilai mampu mengekspresikan identitas para konsumennya melalui nilai tambah yang ditawarkan dalam menciptakan asosiasi yang bermakna tertentu (Ruane \& Wallace, 2015). Self-expressive brand merujuk pada merek-merek yang dirasakan konsumen mampu mencerminkan konsep dirinya atau meningkatkan nilai sosialnya. Keterikatan konsumen terhadap sebuah merek akan semakin meningkat ketika merek tersebut mampu menciptakan identitas konsumennya (Ruane \& Wallace, 2015).

Menurut Wallace et al (2014) self-expressive brand merupakan anteseden utama dari brand love. Merek yang melekat secara emosional dengan konsumen akan meningkatkan persepsi dirinya dan selanjutnya konsumen akan terdorong untuk mengkomunikasikan persepsi semacam itu kepada orang lain. Dengan demikian suatu merek akan makin dicintai oleh konsumennya (Albert dan Merunka, 2013; Huber et al., 2015). Self-expressive brand sebagai sebuah konsep diri ialah bentuk ekspresi diri seorang individu yang ingin ditunjukkan kepada orang lain berkaitan dengan simbol sosial, pencapaian pribadi yang sifatnya lebih individualistik, sebagai bentuk pembeda dari orang lain (Ruane and Wallace, 2015). Batra et al (2012) mengungkapkan adanya hubungan yang positif antara identitas diri dengan penggunaan merek tertentu dan penggunaan merek yang dicintai. Merek juga dapat menjadi sebuah asosiasi sebuah kelompok atau grup, sehingga dengan menggunakan merek tertentu akan menjadikan individu yang menghubungkan ke golongan grup tertentu atau kelompok yang memiliki preferensi merek sejenis (Khare et al., 2012; Ruane and Wallace, 2015).

Selain self-expressive brand, motif hedonis dan utilitarian dalam ikatan konsumen dan merek dalam pembentukan brand love juga telah diakui sebagai variabel yang sangat penting (Grisaffe dan Nguyen, 2011). Pengaruh dari self-expressiveness dan nilai hedonis pada brand love telah ditunjukkan dalam penelitian sebelumnya (Albert dan Merunka, 2013; Huber et al., 2015; Drennan et al., 2015). Sementara penelitian oleh Ramadhania (2017) yang meneliti pengaruh hedonic product terhadap brand loyalty menunjukan tidak memiliki pengaruh signifikan. Disisi lain, self-expressive brand berhubungan dengan brand loyalty telah dibuktikan oleh Ruane dan Wallace (2015) dalam studi mereka. Setiap individu memiliki skema diri yang berbeda-beda salah satunya membangun keterikatan dengan merek tertentu yang pada akhirnya membentuk konsep diri khususnya dari sisi emosional (Wallace et al., 2014). Reaksi dari sikap keterikatan terhadap merek mencakup rasa cinta dan loyalitas terhadap merek tersebut. Brand love merupakan tingkat emosi yang dimiliki oleh konsumen yang puas terhadap suatu merek (Wallace et al., 2014). Konsep dari brand love oleh Batra et al (2012) ialah bagaimana konsumen menggunakan sebuah merek untuk mengekpresikan diri (self-expressive brand) atau untuk merefleksikan bagaimana mereka ingin dilihat oleh orang lain, yang kemudian menciptakan rasa cinta terhadap merek tersebut. Sebagaimana sebuah pasangan yang serasi, ketika citra diri dan citra produk memiliki kesesuaian atau kemiripan maka brand love akan meningkat. (Wallace et al., 2014). Dalam konteks kesetiaan kepada merek yang meraka cintai ini selanjutnya akan terbentuk niat dan komitmen untuk membeli produk (Algharabat, 2017).

Penelitian Wallace et al (2017) menemukan brand love memiliki pengaruh positif pada brand loyalty. Loyalitas terhadap merek dapat berupa keinginan untuk menggunakan, kesediaan untuk menginvestasikan lebih 
banyak sumber daya untuk membeli dan keterlibatan untuk mempromosikan hal-hal positif atau good word of mouth (WOM) dari merek yang dicintai kepada orang lain (Huang, 2017). Brand loyalty didefinisikan sebagai niat untuk loyal terhadap suatu merek dan memberi prioritas untuk membeli merek tersebut dibandingkan dengan merek lain (Ding dan Tseng, 2015). Menurut Liu et al (2012) brand loyalty berkaitan dengan tingkat ketertarikan konsumen terhadap merek tertentu. Jika konsumen tertarik dan menyukai suatu merek, maka konsumen akan memiliki loyalitas yang lebih besar kepada merek tersebut. Sallam (2015) mengidentifikasi bahwa kepuasan yang didapatkan dari hedonic product dapat mempengaruhi brand loyalty. Pernyataan ini tidak selaras dengan penelitian Ramadhina (2017) yang menemukan hedonic product tidak memiliki pengaruh signifikan pada brand loyalty. Dikemukakan bahwa untuk mendapatkan yang konsumen inginkan dari mengkonsumi atau membeli hedonic product yang cenderung memiliki harga tinggi, konsumen harus mengorbankan hal-hal tertentu baik waktu maupun uang mereka. Hedonic product juga dirasakan sebagai euforia singkat sehingga tidak memiliki pengaruh yang signifikan terhadap loyalitas.

Sementara pada self-expressive brand Ruane dan Wallace (2015) menemukan bahwa self-expressive brand memiliki pengaruh secara langsung terhadap brand loyalty. Ramadhania (2017) juga mengidentifikasi bahwa konsumen yang menggunakan self-expressive brand lebih loyal terhadap merek tersebut. Artinya selfexpressive brand memiliki pengaruh yang signifikan terhadap brand loyalty. Ini dikarenakan konsumen yang memilih self-expressive brand adalah konsumen yang memiliki keinginan untuk membedakan identitas dirinya dari orang lain melalui cara yang baik. Sebagaimana yang dinyatakan oleh Ruane dan Wallace (2015), merek yang menawarkan manfaat untuk mengekspresikan diri akan mendorong loyalitas karena merek mampu memenuhi kebutuhan ekspresif dalam diri konsumen. Berdasarkan fenomena-fenomena tersebut maka penelitian memiliki tujuan untuk menguji secara empiris model konseptual yang menjelaskan terbentuknya brand loyalty dan brand love berdasarkan self-expressive brand dan hedonic product dan menganalisis pengaruh langsung dan tidak langsung self-expressive brand dan hedonic product pada brand loyalty.

\section{Metode Penelitian}

Jenis penelitian yang digunakan dalam penelitian ini ialah penelitian asosiatif. Pertanyaan penelitian yang terbentuk memiliki sifat hubungan antara dua atau lebih variabel (Sugiyono, 2012). Objek penelitian dilakukan di Gerai Starbucks Mall Dinoyo Malang tepatnya di JI. MT. Haryono No. 195-197 Malang. Pengambilan obyek penelitian berdasarkan lokasi yang berada di dalam mall dan dekat dengan kampus sehingga menjadi alasan pengunjung dalam mendukung variabel yang diteliti. Pengumpulan data dengan menggunakan metode kuesioner dengan langsung mendatangi lokasi penelitian. Penelitian dilaksanakan pada bulan Februari 2020 April 2020. Penelitian ini digolongkan sebagai penelitian deskriptif kuantitatif dengan 4 macam variabel yaitu Hedonic product $\left(\mathrm{X}_{1}\right)$, Self-expressive $\left(\mathrm{X}_{2}\right)$, Brand Love $\left(\mathrm{Y}_{2}\right)$ dan Brand Loyalty $\left(\mathrm{Y}_{3}\right)$. Jumlah sampel dalam penelitian ini mengikuti pendapat dari Hair (2010) bahwa jumlah sampel yang baik untuk model struktural berkisar $100-200$. Oleh karena itu, penelitian ini dilakukan ini dengan pengumpulan sampel lebih dari 100 dan dengan accidental sampling merupakan metode pengambilan sampel ini, jumlah yang didapatkan selama 1 minggu adalah sebanyak 125 sampel.

Analisis data menggunakan analisis Structural Equation Model (SEM). Dalam SEM dilakukan pengujian model pengukuran untuk uji validitas dan uji reliabilitas instrumen serta goodness of fit model penelitian, pengujian dlilakukan pula pada model struktural untuk pengujian hubungan kausalitas antar variabel (Hair, et.al, 2010). Pengujian asumsi juga dilakukan pada analisis SEM dikarenakan analisis SEM merupakan uji statistik paremetrik, sehingga dilakukan uji asumsi normalitas pada seluruh instrumen penelitian dan identifikasi outlier untuk menghindari bias dalam penelitian. Penulis melakukan pengumpulan data dengan metode accidental sampling yaitu jenis non-probability atau non-random sampling. Metode ini memiliki target sampel dengan kriteria tertentu yaitu akses yang mudah, jangkauan geografis, ketersediaan waktu tertentu, dan keinginan untuk turut berpartisipasi yang kemudian akan disertakan untuk tujuan penelitian (Dörnyei, Z, 2007). Cara pengambilan sampel ini dianggap sebagai pengambilan sampel yang tidak sengaja karena responden yang dipilih kebetulan dekat dengan peneliti yang sedang melakukan data. 
Gambar 1. Kerangka Konsep Penelitian

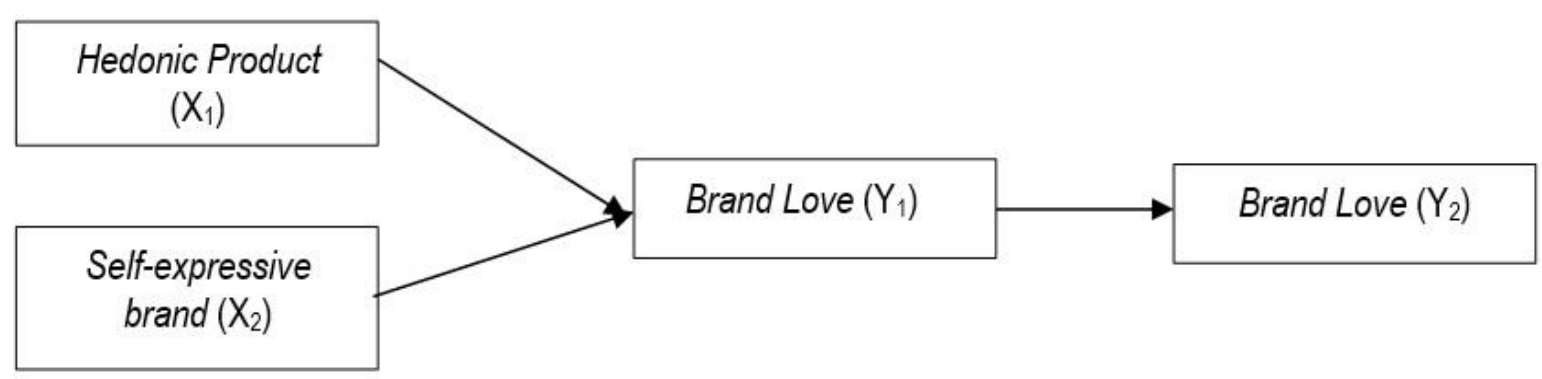

Hasil

Proses analisis dalam penelitian ini dilakukan dengan menggunakan 2 software analisis statistik yaitu IBM SPSS dan IBM AMOS dengan versi yang sama yaitu versi 24.0. Analisis deskriptif pada karakteristik demografi responden pada Tabel 1 menunjukkan bahwa mayoritas pelanggan Starbucks Coffee merupakan wanita, berdasarkan usianya dapat diidentifikasi bahwa mayoritas pelanggan berusia muda yaitu $21-30$ tahun. Usia muda ini berhubungan dengan pendidikan akhir dan juga pekerjaan responden yang mayoritas merupakan pelajar atau mahasiswa dengan pendidikan terakhir SMA.

Tabel 1. Karakteristik Demografi Responden

\begin{tabular}{|c|c|c|c|}
\hline Item & Karakteristik & Frekuensi & $(\%)$ \\
\hline \multirow{2}{*}{ Jenis Kelamin } & Perempuan & 80 & 64,0 \\
\hline & Laki-Laki & 45 & 36,0 \\
\hline \multirow[t]{5}{*}{ Usia } & $<=20$ Tahun & 21 & 16,8 \\
\hline & 21 - 30 Tahun & 94 & 75,2 \\
\hline & 31 - 40 Tahun & 6 & 4,8 \\
\hline & 41- 50 Tahun & 3 & 2,4 \\
\hline & > 50 Tahun & 1 & 0,8 \\
\hline \multirow[t]{6}{*}{ Pendidikan Terakhir } & $\mathrm{SD}$ & 2 & 1,6 \\
\hline & SMP & 1 & 0,8 \\
\hline & SMA & 84 & 67,2 \\
\hline & Diploma & 1 & 0,8 \\
\hline & Sarjana & 33 & 26,4 \\
\hline & Pasca Sarjana & 4 & 3,2 \\
\hline \multirow[t]{5}{*}{ Pekerjaan } & Pelajar/Mahasiswa & 97 & 77,6 \\
\hline & Wirausaha & 8 & 6,4 \\
\hline & PNS & 6 & 4,8 \\
\hline & Pegawai Swasta & 13 & 10,4 \\
\hline & Lainnya & 1 & 0,8 \\
\hline \multirow[t]{3}{*}{ Penghasilan Perbulan } & $<\operatorname{Rp} 1.000 .000$ & 37 & 29,6 \\
\hline & Rp 1.000.000 - Rp. 1.999 .999 & 38 & 30,4 \\
\hline & $\begin{array}{l}\operatorname{Rp} 2.000 .000 \text { - Rp. } 2.999 .999 \\
\Rightarrow \operatorname{Rp} 3.000 .000\end{array}$ & $\begin{array}{l}23 \\
27\end{array}$ & $\begin{array}{l}18,4 \\
216\end{array}$ \\
\hline \multirow[t]{4}{*}{ Frekuensi Pembelian } & 1 bulan sekali & 60 & 48,0 \\
\hline & $2-3$ bulan sekali & 25 & 20,0 \\
\hline & $4-5$ bulan sekali & 19 & 15,2 \\
\hline & $>5$ bulan sekali & 21 & 16,8 \\
\hline
\end{tabular}

Sumber : Data primer diolah, 2020

Penelitian ini mengidentfikasi bahwa pelanggan Starbucks Coffee di Malang lebih didominasi oleh kalangan anak muda terutama pelajar/mahasiswa sehingga yang mayoritas hanya 1 bulan sekali melakukan 
pembelian. Minimnya frekuensi pembelian perbulan dapat dipahami karena mayoritas pelanggan memiliki penghasilan menengah yaitu Rp 1.000.000 - Rp. 1.999 .999 perbulan. Hasil analisis data penelitian pada Tabel 2 menemukan bahwa nilai skor jawaban rata-rata responden pada tiap variabel laten dalam penelitian ini berkisar antara $2,73-3,37$. Nilai rata-rata untuk semua variabel mengindikasikan tanggapan yang relatif sedang, sehingga dapat diketahui bahwa responden memiliki tingkat hedonic product $\left(X_{1}\right)$, self-expressive brand $\left(X_{2}\right)$, brand love $\left(\mathrm{Y}_{1}\right)$, dan brand loyalty $\left(\mathrm{Y}_{2}\right)$ sedang.

Tabel 2. Deskripsi Jawaban Responden dan Korelasi antar Variabel Laten

\begin{tabular}{ccccccc}
\hline & Mean & $\mathrm{SD}$ & $\mathrm{HP}\left(\mathrm{X}_{1}\right)$ & $\mathrm{SB}\left(\mathrm{X}_{2}\right)$ & $\mathrm{BLV}\left(\mathrm{Y}_{1}\right)$ & $\mathrm{BL}\left(\mathrm{Y}_{2}\right)$ \\
\hline $\mathrm{HP}\left(\mathrm{X}_{1}\right)$ & 3,37 & 0.41 & 0,812 & & & \\
\hline $\mathrm{SB}\left(\mathrm{X}_{2}\right)$ & 2,73 & 0.22 & 0,611 & 0,879 & & \\
\hline $\operatorname{BLV}\left(\mathrm{Y}_{1}\right)$ & 3,37 & 0.36 & 0,788 & 0,759 & 0,843 & \\
\hline $\mathrm{BL}\left(\mathrm{Y}_{2}\right)$ & 2,97 & 0.22 & 0,576 & 0,683 & 0,762 & 0,861 \\
\hline
\end{tabular}

Sumber : Data primer diolah, 2020

Korelasi antar variabel laten dalam Tabel 2 menunjukkan bahwa koefisien korelasi pada tiap variabel bernilai lebih dari 0,5. Koefisien korelasi yang cukup tinggi mengindikasikan adanya hubungan yang erat antar variabel laten dalam penelitian ini. Koefisien korelasi ini berikutnya dibandingkan dengan akar dari Average Variance Extracted (AVE) untuk mengetahui apakah konstruk variabel laten memperlihatkan discriminant validity yang baik. Perbandingan akar AVE dengan koefisien antar variabel laten menunjukkan bahwa koefisien korelasi antar variabel laten dengan laten lainnya dalam model lebih kecil dibandingkan dengan nilai akar AVE. Hasil perbandingan konstruk variabel laten pada penelitian ini menunjukan discriminant validity yang baik.

Evaluasi model konstruk tiap variabel laten dilakukan dengan menggunakan analisis faktor konfirmatori (CFA) untuk mengetahui apakah instrumen pengukuran/ variabel manifest dalam penelitian ini mampu dan handal dalam menggambarkan variabel laten. Tabel 3 menunjukkan seluruh item pertanyaan pada kuisioner nilai loading factor lebih dari 0,5 yang berarti instrumen penelitian mempunysi convergent validity yang baik. Dengan demikian hasil CFA mengkonfirmasi bahwa variabel manifest dalam penelitian ini dapat menggambarkan konstruk variabel laten dengan baik dan unik sehingga tidak memiliki ambiguitas dengan konstruk variabel laten lainnya dalam model penelitian.

Reliabilitas konstruk variabel laten kemudian diuji setelah diketahui bahwa konstruk variabel laten memiliki validitas yang baik. Nilai Cronbach's Alpha (a) hasil CFA pada tiap variabel laten bernilai antara 0,893 0,958. Nilai Cronbach's Alpha yang didapatkan melalui CFA memperlihatkan nilai yang lebih besar dibandingkan 0,6 yang mengindikasikan model kosntruk tiap variabel reliabel. Hasil temuan ini selaras dengan pengujuan reliabilitas menggunakan composite reliability. Nilai composite reliability (CR) pada tiap variabel laten dalam penelitian bernilai lebih besar dari 0,7 yang juga mengindikasikan bahwa konstruk variabel laten memiliki reliabilitas yang baik.

Evaluasi model konstruk menunjukkan bahwa variabel laten dalam penelitian ini telah diukur dengan baik dan reliabel, sehingga evaluasi dapat dilanjutkan pada model struktural. Evaluasi model struktural dilakukan untuk mengetahui model goodness of fit. Seperti yang terlihat pada Tabel 4 yang merupakan hasil goodness of fit menunjukkan bahwa model struktural tidak memenuhi seluruh kriteria goodness of fit, sehingga perlu dilakukan modifikasi pada model. 
Tabel 3. Hasil Analisis Faktor Konfirmatori (CFA)

\begin{tabular}{|c|c|c|c|c|c|}
\hline Construct & Item & Loading Factor & $a$ & AVE & CR \\
\hline \multirow{6}{*}{$\begin{array}{c}\text { Hedonic Product } \\
\text { (X1) }\end{array}$} & HP1 & 0,872 & \multirow{6}{*}{0,893} & \multirow{6}{*}{0,670} & \multirow{6}{*}{0,923} \\
\hline & $\mathrm{HP} 2$ & 0,827 & & & \\
\hline & HP3 & 0,789 & & & \\
\hline & $\mathrm{HP} 4$ & 0,716 & & & \\
\hline & HP5 & 0,710 & & & \\
\hline & HP6 & 0,781 & & & \\
\hline \multirow{8}{*}{$\begin{array}{l}\text { Self-expressive Brand } \\
\qquad\left(X_{2}\right)\end{array}$} & SB1 & 0,967 & \multirow{8}{*}{0,958} & \multirow{8}{*}{0,773} & \multirow{8}{*}{0,965} \\
\hline & SB2 & 0,946 & & & \\
\hline & SB3 & 0,905 & & & \\
\hline & SB4 & 0,949 & & & \\
\hline & SB5 & 0,894 & & & \\
\hline & SB6 & 0,919 & & & \\
\hline & SB7 & 0,722 & & & \\
\hline & SB8 & 0,738 & & & \\
\hline \multirow{8}{*}{$\begin{array}{l}\text { Brand Love } \\
\left(\mathrm{Y}_{1}\right)\end{array}$} & BLV1 & 0,626 & \multirow{8}{*}{0,940} & \multirow{8}{*}{0,710} & \multirow{8}{*}{0,951} \\
\hline & BLV2 & 0,872 & & & \\
\hline & BLV3 & 0,816 & & & \\
\hline & BLV4 & 0,898 & & & \\
\hline & BLV5 & 0,868 & & & \\
\hline & BLV6 & 0,816 & & & \\
\hline & BLV7 & 0,852 & & & \\
\hline & BLV8 & 0,772 & & & \\
\hline \multirow{8}{*}{$\begin{array}{l}\text { Brand Loyalty } \\
\qquad\left(\mathrm{Y}_{2}\right)\end{array}$} & BL1 & 0,855 & \multirow{8}{*}{0,948} & \multirow{8}{*}{0,742} & \multirow{8}{*}{0,958} \\
\hline & BL2 & 0,791 & & & \\
\hline & BL3 & 0,765 & & & \\
\hline & BL4 & 0,900 & & & \\
\hline & BL5 & 0,896 & & & \\
\hline & BL6 & 0,884 & & & \\
\hline & BL7 & 0,931 & & & \\
\hline & BL8 & 0,734 & & & \\
\hline
\end{tabular}

Sumber : Data primer diolah, 2020

Modifikasi model dilakukan dengan melihat modification indices pada analisis SEM yang telah dilakukan. Modification indices pada dasarnya menunjukkan peningkatan nilai goodness of fit dengan menghubungkan sejumlah variabel dalam penelitian yang semula tidak dihubungkan dalam model. Modifikasi model dilakukan pada residual/error agar tidak merubah hipotesis serta tidak memperluas bahasan penelitian. Hasil modifikasi model digambarkan pada Gambar 1 yang menunjukkan keterkaitan antar error dalam model.

Tabel 4. Hasil Evaluasi Goodness of Fit Model

\begin{tabular}{ccc}
\hline Kriteria Goodness of Fit & Nilai & Keterangan \\
\hline $\mathrm{p}$-value $\mathrm{X}^{2}$ & 0,000 & Model tidak fit \\
$\mathrm{X}^{2} / \mathrm{df}$ & 3,188 & Model tidak fit \\
GFI & 0,560 & Model tidak fit \\
$\mathrm{AGFI}$ & 0,487 & Model tidak fit \\
$\mathrm{CFI}$ & 0,800 & Model tidak fit \\
TLI & 0,781 & Model tidak fit \\
RMSEA & 0,133 & Model tidak fit \\
\hline
\end{tabular}

Sumber : Data primer diolah, 2020 
Gambar 2. Hasil Modifikasi Model

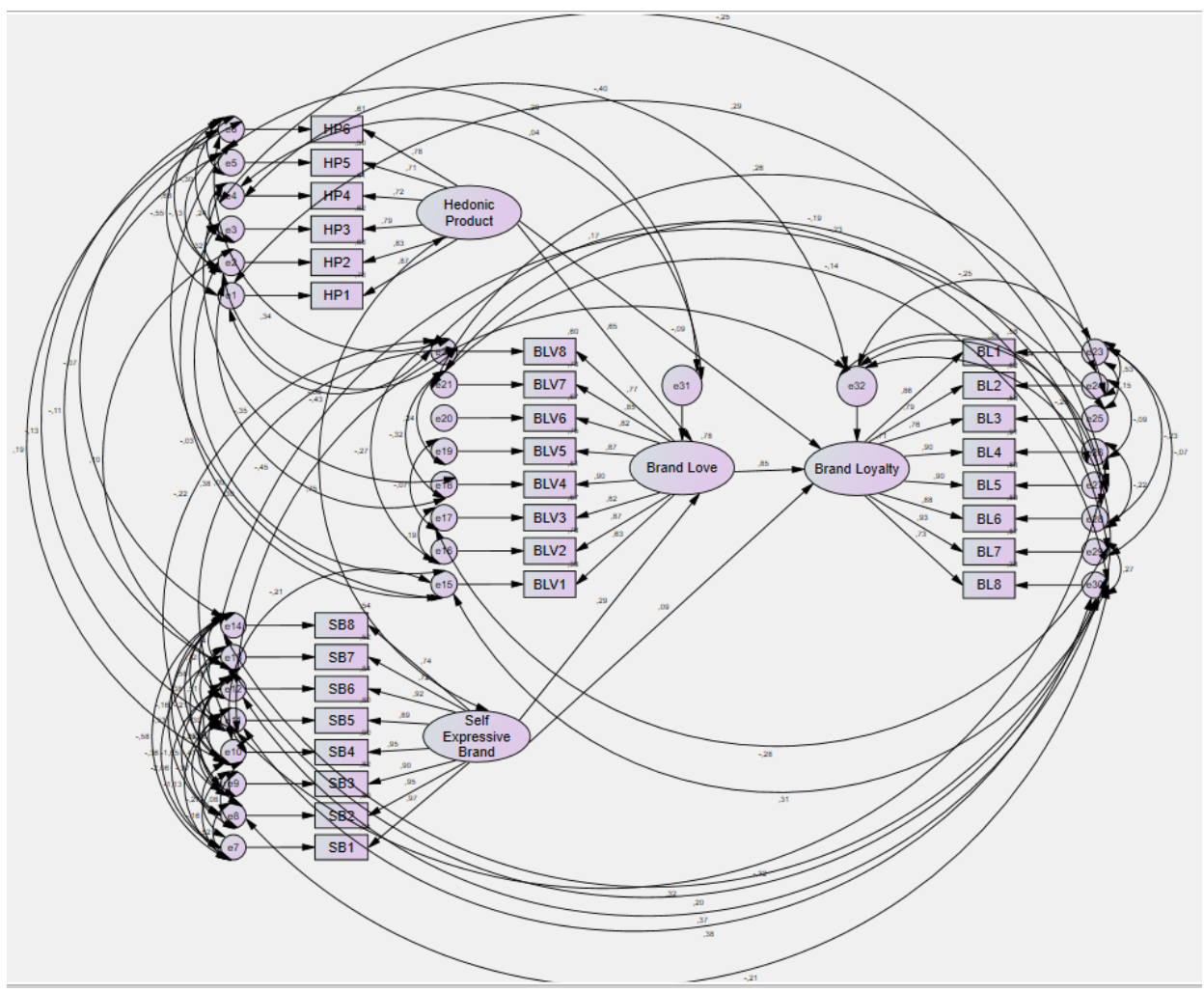

Modifikasi model yang dilakukan berhasil meningkatkan goodness of fit model hal ini sesuai dengan pendapat Kline (2016). Tabel 5 menunjukkan bahwa terdapat 4 kriteria yang memenuhi GOF yaitu $X^{2} / \mathrm{df}, \mathrm{CFI}$, $\mathrm{TLI}$, dan RMSEA. Adanya kriteria yang memenuhi GOF menggambarkan bahwa model dalam penelitian ini layak dan dapat digunakan dalam penelitian selanjutnya.

Tabel 5. Hasil Evaluasi Goodness of Fit Model setelah Modifikasi

\begin{tabular}{ccc}
\hline Kriteria Goodness of Fit & Nilai & Keterangan \\
\hline $\mathrm{p}$-value $\mathrm{X}^{2}$ & 0,000 & Model tidak fit \\
$\mathrm{X}^{2} / \mathrm{df}$ & 1,476 & Model fit \\
$\mathrm{AGFI}$ & 0,813 & Model tidak fit \\
$\mathrm{GFI}$ & 0,724 & Model tidak fit \\
$\mathrm{CFI}$ & 0,952 & Model fit \\
TLI & 0,966 & Model fit \\
RMSEA & 0,062 & Model fit \\
\hline
\end{tabular}

Sumber : Data primer diolah, 2020

Ketercapaian GOF model memberikan ruang bagi peneliti untuk melakukan pengujian hipotesis penelitian untuk mengetahui pengaruh antara variabel independen dan derpenden pada penelitian ini. Pengaruh variabel independen dilihat melalui koefisien jalur dari variabel independen terhadap variabel dependen yang dipengaruhi. Kebermaknaan pengaruh dinilai melalui nilai $p$-value, nilai $p$-value lebih kecil dari a $(0,05)$ yang artinya variabel independen memiliki pengaruh yang bermakna terhadap variabel dependen. 
Tabel 6. Hasil Pengujian Hipotesis Pengaruh Langsung

\begin{tabular}{ccccc}
\hline Pengaruh Langsung & Koefisien Jalur & CR & p-value & $\mathbf{R}^{2}$ \\
\hline $\mathrm{HP}\left(\mathrm{X}_{1}\right) \rightarrow \operatorname{BLV}\left(\mathrm{Y}_{1}\right)$ & 0,647 & 5,647 & 0,000 & \multirow{2}{*}{0,784} \\
$\mathrm{SB}\left(\mathrm{X}_{2}\right) \rightarrow \operatorname{BLV}\left(\mathrm{Y}_{1}\right)$ & 0,291 & 3,635 & 0,000 & \\
$\mathrm{BLV}\left(\mathrm{Y}_{1}\right) \rightarrow \mathrm{BL}\left(\mathrm{Y}_{2}\right)$ & 0,847 & 5,269 & 0,000 & \\
$\mathrm{HP}\left(\mathrm{X}_{1}\right) \rightarrow \mathrm{BL}\left(\mathrm{Y}_{2}\right)$ & $-0,088$ & $-0,788$ & 0,431 & 0,709 \\
$\mathrm{SB}\left(\mathrm{X}_{2}\right) \rightarrow \mathrm{BL}\left(\mathrm{Y}_{2}\right)$ & 0,089 & 1,257 & 0,209 & \\
\hline
\end{tabular}

Sumber : Data primer diolah, 2020

Teknik boothstrap digunakan dalam pengujian hipotesis dikarenakan asumsi normalitas gagal terpenuhi. Westland (2009) menyatakan bahwa penggunakan boothstrap akan mengatasi permasalahan normalitas yang dihadapi saat melakukan analisis parametrik seperti SEM. Hasil pengujian hipotesis menunjukkan bahwa hedonic product $\left(\mathrm{X}_{1}\right)$ dan self-expressive brand $\left(\mathrm{X}_{2}\right)$ mempunyai pengaruh positif dan signifikan terhadap brand love dilihat dari nilai koefisien jalur bernilai positif dan $p$-value kurang dari 0,05 . Nilai R-square sebesar 0,784 merepresentasikan peran hedonic product $\left(X_{1}\right)$ dan self-expressive brand $\left(X_{2}\right)$ dalam mempengaruhi brand love $\left(Y_{1}\right)$ sebesar $78,4 \%$ sementara 21,6\% sisanya dipengaruhi oleh variabel lain di luar penelitian.

Pengujian hipotesis juga memperlihatkan bahwa dari tiga variabel yang berpengaruh langsung terhadap brand loyalty $\left(Y_{2}\right)$ yaitu hedonic product $\left(X_{1}\right)$, self-expressive brand $\left(X_{2}\right)$, dan brand love $\left(Y_{1}\right)$ hanya brand love $\left(Y_{1}\right)$ yang terbukti memiliki pengaruh signifikan terhadap brand loyalty $\left(Y_{2}\right)$. Hedonic product $\left(X_{1}\right)$, self-expressive brand $\left(\mathrm{X}_{2}\right)$, dan brand love $\left(\mathrm{Y}_{1}\right)$ berperan dalam mempengaruhi brand loyalty $\left(\mathrm{Y}_{2}\right)$ sebesar $70,9 \%$ sedangkan $29,1 \%$ lainnya dipengaruhi variabel lain yang tidak diikutsertakan pada penelitian. Dengan demikian penelitian ini menyimpulkan bahwa hedonic product $\left(\mathrm{X}_{1}\right)$ dan self-expressive brand $\left(\mathrm{X}_{2}\right)$ tidak terbukti berpengaruh langsung terhadap brand loyalty $\left(\mathrm{Y}_{2}\right)$. Meskipun hedonic product $\left(\mathrm{X}_{1}\right)$ dan self-expressive brand $\left(\mathrm{X}_{2}\right)$ tidak terbukti mempunyai pengaruh langsung pada brand loyalty namun terdapat adanya indikasi terdapat pengaruh tidak langsung yang diberikan oleh hedonic product $\left(X_{1}\right)$ dan self-expressive brand $\left(X_{2}\right)$ terhadap brand loyalty yang diidentifikasi dari adanya pengaruh hedonic product $\left(\mathrm{X}_{1}\right)$ dan self-expressive brand $\left(\mathrm{X}_{2}\right)$ terhadap brand love $\left(\mathrm{Y}_{1}\right)$, dimana brand love $\left(\mathrm{Y}_{1}\right)$ juga terbukti menunjukkan pengaruh yang signifikan terhadap brand loyalty $\left(\mathrm{Y}_{2}\right)$. Sobel test dilakukan untuk membuktikan adanya indikasi pengaruh tidak langsung yang signifikan dari hedonic product $\left(\mathrm{X}_{1}\right)$ dan self-expressive brand $\left(\mathrm{X}_{2}\right)$ terhadap brand loyalty $\left(\mathrm{Y}_{2}\right)$ melalui brand love $\left(\mathrm{Y}_{1}\right)$.

Tabel 7. Hasil Pengujian Hipotesis Pengaruh Tidak Langsung

\begin{tabular}{cccc}
\hline Pengaruh Langsung & Koefisien Jalur & CR & p-value \\
\hline $\mathrm{HP}\left(\mathrm{X}_{1}\right) \rightarrow \mathrm{BLV}\left(\mathrm{Y}_{1}\right) \rightarrow \mathrm{BL}\left(\mathrm{Y}_{2}\right)$ & 0,548 & 3,859 & 0,000 \\
$\mathrm{SB}\left(\mathrm{X}_{2}\right) \rightarrow \mathrm{BLV}\left(\mathrm{Y}_{1}\right) \rightarrow \mathrm{BL}\left(\mathrm{Y}_{2}\right)$ & 0,246 & 2,990 & 0,003 \\
\hline
\end{tabular}

Sumber : Data primer diolah, 2020

Koefisien jalur dan $p$-value pada Tabel 7 menunjukkan bahwa indikasi pengaruh tidak langsung terbukti pada pengujian hipotesis. Koefisien jalur bernilai positif dan p-value lebih kecil dari 0.05. ini berarti bahwa hedonic product $\left(\mathrm{X}_{1}\right)$ dan self-expressive brand $\left(\mathrm{X}_{2}\right)$ berpengaruh tidak langsung yang positif dan signifikan terhadap brand loyalty $\left(Y_{2}\right)$ melalui perantara brand love $\left(Y_{1}\right)$. Koefisien jalur hedonic product lebih besar dibandingkan self-expressive brand $\left(\mathrm{X}_{2}\right)$ menunjukkan bahwa hedonic product $\left(\mathrm{X}_{1}\right)$ lebih dominan dalam mempengaruhi brand loyalty $\left(\mathrm{Y}_{2}\right)$ dibandingkan self-expressive brand $\left(\mathrm{X}_{2}\right)$. Hasil pengujian hipotesis tidak langsung juga menyimpulkan bahwa brand love $\left(Y_{1}\right)$ memiliki peran yang signfikan sebagai mediator yang memperantarai pengaruh hedonic product $\left(\mathrm{X}_{1}\right)$ dan self-expressive brand $\left(\mathrm{X}_{2}\right)$ terhadap brand loyalty $\left(\mathrm{Y}_{2}\right)$.

\section{Pembahasan}

Penelitian ini mengidentifikasi beberapa temuan. Pertama, sesuai dengan hipotesis 1 , hedonic product $\left(X_{1}\right)$ mempunyai pengaruh yang positif dan juga signifikan terhadap brand love $\left(Y_{1}\right)$. Temuan ini sama dengan temuan dari studi sebelumnya oleh Hwang and Kandampully (2012), Huber et al., (2015) dan Maehe et al (2015), yang mengemukakan bahwa nilai hedonis yang diperoleh dari hedonic product dapat memenuhi kebutuhan prestis konsumen dan mampu menumbuhkan rasa cinta terhadap merek tersebut. Pelanggan 
Starbucks Coffee merasakan dengan mengonsumsi produk Starbucks Coffee mampu memberikan manfaat hedonis berupa kesenangan, kebahagiaan dan kenikmatan. Selain itu membeli produk Starbucks Coffee dinilai oleh pelanggannya merupakan sebuah kebutuhan dan sebagai bentuk life reward.

Temuan kedua sebagaimana hipotesis 2 yaitu self-expressive brand $\left(\mathrm{X}_{2}\right)$ menunjukan pengaruh positif dan signifikan terhadap brand love $\left(Y_{1}\right)$. Temuan inimendukung penelitian oleh Batra et al (2012) dan Wallace et al (2014). Dalam studi sebelumnya ditemukan bahwa brand yang memiliki keterikatan emosional dan mampu menjadi ekspresi identitas konsumennya akan makin dicintai. Hasil dari penelitian ini menunjukkan bahwa pelanggan mencintai brand Starbucks Coffee karena menganggap produk Starbucks Coffee dapat mengekspresikan citra dan personaliti serta simbol sosial yang ingin ditunjukkan kepada orang lain.

Selanjutnya hipotesis 3 menyatakan Brand love $\left(Y_{1}\right)$ berpengaruh yang positif terhadap brand loyalty $\left(Y_{2}\right)$. Penelitian terdahulu oleh Wallace et al (2017) mendukung penelitian ini yang membuktikan bahwa brand love $\left(Y_{1}\right)$ menjadi variabel utama yang memiliki pengaruh signifikan terhadap brand loyalty $\left(Y_{2}\right)$. Berdasarkan hasil penelitian ini, pelanggan Starbucks Coffee di Malang setuju bahwa Starbucks Coffee merupakan sebuah merek yang hebat, produknya membuat pelanggan senang sehingga pelanggan merasa sangat terikat terhadap brand ini. Selain itu desain gerai Starbucks Coffee yang modern dan semi outdoor, sangat cocok dengan gaya kalangan muda. Citra tersebut membuat Starbucks Coffee dicintai oleh konsumennya karena dianggap mencerminkan citra diri konsumen. Hal tersebut yang kemudian membuat pelanggan selalu membeli produknya dan menjadi loyal.

Temuan terakhir berdasarkan hipotesis 4 dan 5 yaitu hedonic product $\left(X_{1}\right)$ dan self-expressive brand $\left(X_{2}\right)$ berpengaruh tidak langsung yang positif dan signifikan pada brand loyalty melalui brand love. Brand love $\left(Y_{1}\right)$ memiliki peran signifikan sebagai mediator. Sementara itu, hedonic product $\left(X_{1}\right)$ lebih dominan dalam mempengaruhi brand loyalty dibandingkan self-expressive brand $\left(\mathrm{X}_{2}\right)$. Temuan ini membantah studi sebelumnya oleh Ramadhania (2017). Hasil penelitian menunjukkan bahwa kepuasan yang didapatkan dengan mengkonsumsi produk hedonis yang cenderung memiliki harga tinggi memberikan pengaruh lebih besar dalam mendorong perilaku pembelian dan kesetiaan terhadap suatu merek. Dengan membeli produk Starbucks Coffee dinilai konsumen lebih mampu memberikan kepuasaan dalam bentuk terpenuhinya kebutuhan prestis. Namun kepuasan dan kemampuan brand untuk menjadi media dalam mengekspresikan diri, terlebih dahulu harus menciptakan rasa cinta terhadap brand. Setelah konsumen terikat secara emosional maka akan mempengaruhi kesetiaan untuk membeli.

\section{Kesimpulan}

Berdasarkan paparan serta uraian hasil penelitian dan pembahasan terhadap brand love dan brand loyalty pelanggan pada Starbucks Coffee di Malang dapat ditarik kesimpulan bahwa hedonic product berpengaruh secara positif dan signifikan terhadap brand love. Hasil temuan ini menunjukan produk Starbucks Coffee merupakan produk yang dikategorikan sebagai barang mewah dengan brand ternama. Brand ini pun mampu meraih rasa cinta pelanggannya. Self-expressive brand juga menunjukan pengaruh yang positif dan signifikan terhadap brand love. Pelanggan dapat menunjukkan jati diri secara personal maupun berkelompok dengan cara mencintai brand Starbucks Coffee. Sementara itu, brand love memiliki pengaruh yang positif terhadap brand loyalty. Rasa cinta yang besar pada suatu merk ditandai dengan cara menjadi pelanggan loyal Starbuck Coffee. Namun, pada penelitian ini menunjukan bahwa hedonic product dan self-expressive brand tidak terbukti berpengaruh langsung terhadap brand loyalty. Pernyataan tersebut dapat dikatakan bahwa untuk membentuk pelanggan loyal pada suatu brand atau merk tidak dapat dicapai langsung hanya dengan hedonic product dan self-expressive brand namun harus melalui brand love terlebih dahulu. Hal ini dikarenakan hedonic product dan self-expressive brand berpengaruh secara tidak langsung secara positif dan signifikan terhadap brand loyalty melalui brand love.

Penelitian ini memiliki beberapa keterbatasan sehingga kemungkinan mempengaruhi hasil penelitian secara keseluruhan. Pertama, sampel penelitian berjumlah 125 responden pelanggan Starbucks Coffee di Kota Malang. Untuk penelitian selanjurnya diharapkan mampu mengambil lebih banyak sampel sehingga dapat lebih mewakili populasi pelanggan Starbucks Coffee di Malang dan hasil penelitian memperoleh hasil yang lebih baik. Kedua, metode dalam penelitian ini menggunakan teknik pengambilan data accidental sampling. Dalam penelitian kedepannya disarankan untuk menggunakan metode yang berbeda seperti penggunaan teknik purposive sampling dengan menambahkan kriteria pembelian konsumen yaitu minimal telah 3 kali melakukan pembelian produk Starbucks Coffee. Ketiga, untuk studi selanjutnya sebaiknya perlu mengikutsertakan pertimbangan dari faktor eksternal seperti kualitas layanan dan marketing mix yang mampu membangun brand love. Keempat, objek dalam penelitian hanya terbatas pada gerai-gerai Starbucks Coffee di Malang. Penelitian 
selanjutnya dapat menjangkau objek penelitian yang lebih luas di wilayah yang berbeda atau objek penelitian dari merek yang berbeda sehingga terdapat perbandingan hasil penelitian.

Terakhir, dipandang dari sisi implikasi terhadap manajemen Starbucks Coffee, sebagaimana hasil studi ini dinyatakan bahwa brand love memiliki peran yang kuat untuk membangun brand loyalty. Oleh karena itu, membangun brand love menjadi penting untuk marketer demi menjalin hubungan yang kuat dan loyal antara merek dan pelanggannya. Strategi yang dapat ditempuh oleh Starbucks Coffee iyalah mendorong konsumen untuk menjadi anggota atau member Starbucks Coffee. Hal ini dapat meningkatkan hubungan antara brandkonsumen misalnya melalui program loyalty atau Starbucks Coffee Rewards dan juga meningkatkan pengalaman dalam bertransaksi. Konsumen yang puas dengan performa layanan tersebut akan membangun keterikatan emosional yang kuat dengan merek sehingga menjadi lebih loyal.

\section{Daftar Pustaka}

Albert, N. and Merunka, D. 2013. The role of brand love in consumer-brand relationships. Journal of Consumer Marketing, Vol. 30 No. 3, pp. 258-266.

Alex, N. J., \& Joseph, A. 2012. Hedonic Versus Utilitarian Values: The Relative Importance of Real and Ideal Self to Brand Personality and Its Influence on Emotional Brand Attachment. Vilakshan: The XIMB Journal of Management, 9(2).

Batra, R., Ahuvia, A., \& Bagozzi, R. P. 2012. Brand love. Journal of marketing, 76(2), 1-16.

Carvalho, N. B., Minim, V. P. R., Nascimento, M., Vidigal, M. C. T. R., Ferreira, M. A. M., 902 Gonçalves, A. C. A., \& Minim, L. A. 2015. A discriminant function for validation of 903 the cluster analysis and behavioral prediction of the coffee market. Food Research 904 International, 77, 400-40.

Cramer, L., \& Antonides, G. 2011. Endowment effects for hedonic and utilitarian food products. Journal of Food quality and preference, 22(1), 3-10.

Drennan, J., Bianchi, C., Cacho-Elizondo, S., Louriero, S., Guibert, N., \& Proud, W. 2015. Examining the role of wine brand love on brand loyalty: A multi-country comparison. International Journal of Hospitality Management, 49, 47-55.

Grisaffe, D. B., \& Nguyen, H. P. 2011. Antecedents of emotional attachment to brands. Journal of business research, 64(10), 1052-1059.

Hoyer, W. D., \& Stokburger-Sauer, N. E. 2012. The role of aesthetic taste in consumer behavior. Journal of the Academy of Marketing Science, 40(1), 167-180.

Huber, F., Meyer, F., \& Schmid, D. A. 2015. Brand love in progress-the interdependence of brand love antecedents in consideration of relationship duration. Journal of Product \& Brand Management.

Hwang, J \& Kandampully, J. 2012. The role of emotional aspects in younger consumer-brand relationships. Journal of Product \& Brand Management. Vol. 21 Iss: 2 pp. 98 - 108

International Coffee Organization (ICO). 2015. Global Coffee Forum, 2015. Milan. Diakses 1 Juli 2020

Labbe, D., Ferrage, A., Rytz, A., Pace, J., \& Martin, N. 2015. Pleasantness, emotions and perceptions induced by coffee beverage experience depend on the consumption motivation (hedonic or utilitarian). Journal of Food quality and preference, 44, 56-61.

Langner, T., Schmidt, J., \& Fischer, A. 2015. Is it really love? A comparative investigation of the emotional nature of brand and interpersonal love. Psychology \& Marketing, 32(6), 624-634.

Lu, J. \& Liu, Z. \& Fang, Z. 2016. Hedonic products for you, utilitarian products for me. Judgment and Decision Making, Vol. 11, No. 4, July 2016, pp. 332-341

Messina, R. 2018. Hedonic and utilitarian aspects of coffee consumption in China. BS thesis. Università Ca'Foscari Venezia.

Manzo, J. 2014. Machines, People, and Social Interaction in "Third-Wave " Coffeehouses. Journal of Arts and Humanities (JAH), Volume -3, No.-8, August, 2014.

Putlia, G., 2018 . Konsumerisme Mahasiswa Terhadap Starbucks Coffee Dalam Kerangka Teori Fetisisme Komoditas Dan Motivasi Hedonis. National Conference of Creative Industry: Sustainable Tourism Industry for Economic Development iversitas Bunda Mulia, Jakarta, 5-6 September 2018.

Rahmania, Wahida. 2016. Starbucks Hadir di Malang. https://www.malangtimes.com/

Ramadhina, F.A. 2017. The influence of hedonic product, self-expressive brand, and satisfication on brand love 
and brand loyalty: study of starbucks' consumers in Malang. Jurnal IImiah Mahasiswa FEB, Vol 5, No 2: Semester Genap 2016/2017.

Ruane, L. and Wallace, E. 2015. Brand tribalism and self-expressive brands: social influences and brand outcomes. Journal of Product \& Brand Management, Vol. 24 No. 4, pp. 333-348.

Shirdastian, H., Laroche, M., \& Richard, M. O. 2019. Using big data analytics to study brand authenticity sentiments: The case of Starbucks on Twitter. International Journal of Information Management, 48, 291-307.

Sugiyono, M. 2012. Metode Penelitian Kuantitatif R\&D. Bandung: Alfabeta.

Wallace, E., Buil, I., and Chernatony, L.d. 2014. Consumer engagement with self-expressive brands: brand love and WOM outcomes. Journal of Product \& Brand Management, Vol. 23 No. 1, pp. 33-42.

Wisnubrata. 2017. Starbucks dan Cerita Mereka yang Berkunjung ke Indonesia. https://lifestyle.kompas.com/ 